\title{
Inclusão educacional de crianças com deficiências: notas do chão da escola
}

\author{
Marcos Cezar de Freitas ${ }^{1}$ \\ http://orcid.org/0000-0003-1050-415X \\ Rosângela Nezeiro da Fonseca Jacob² \\ http://orcid.org/0000-0002-1689-506X
}

\section{Resumo}

0 tema deste artigo é a inclusão de crianças com deficiência na educação pública. 0 problema de pesquisa apresentado tem origem nos debates sobre a vida escolar inclusiva e diz respeito às situações concretas que foram analisadas no cotidiano de duas escolas. 0 objetivo principal foi acompanhar o acesso de crianças em cujo registro de matrícula são mencionadas deficiência múltipla ou paralisia cerebral. Desse objetivo, foi organizada a estratégia de observar os diferentes modos de participação e registrar, para análise em detalhes, as cenas em que o acesso não conduziu a uma vida escolar inclusiva e as cenas que, em sentido oposto, revelaram uma dinâmica de participação que resultou em procedimentos inclusivos. Metodologicamente, a coleta de informações, o registro em cadernos de campo e as muitas horas de observação resultaram de etnografias realizadas a partir de 2014 nas escolas públicas identificadas previamente para a pesquisa. Referências antropológicas foram utilizadas. Os principais resultados foram obtidos com inventários de gestos e procedimentos recolhidos em escala microscópica, que indicaram haver dependência entre estratégias inclusivas e abordagens com foco no trabalho pedagógico como um todo e para todos os alunos. Quando a abordagem restringiu-se ao isolamento das crianças para evitar que suas particularidades atrapalhassem os demais, o acesso claramente não ofereceu um modo de participar compatível com uma vida escolar inclusiva. 0 texto apresenta, em suas conclusões, uma análise sobre as cenas focadas e, com base na pesquisa feita, sustenta que acesso nem sempre resulta em inclusão.

\section{Palavras-chave}

Acesso - Participação - Vida escolar inclusiva.

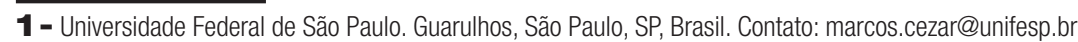

2- Secretaria Municipal de Educação de São Paulo, São Paulo, SP, Brasil. Contato: ronezeiro@uol.com.br 


\section{Educational inclusion of children with disabilities: notes from the school floor}

\section{Abstract}

The subject of this article is the inclusion of children with disabilities in public education. The research question originates in the debates about inclusive school life and concerns the tangible situations that were analyzed in the daily life of two schools. The main objective was to follow the access of children in whose enrollment are mentioned as having multiple disabilities and cerebral palsy. The strategy of observing the different modes of participation and recording was organized around this main objective, for detailed analysis, including the scenes in which the access did not lead to actual inclusive school life and the scenes that, in the opposite direction, revealed a dynamic of participation that resulted in inclusive procedures. Methodologically, the collection of information, recorded in field notebooks, and the many hours observation resulted from ethnographies, conducted since 2014 in public schools previously identified for the study. Anthropological references were used. The main results were obtained through inventories of gestures and procedures collected on a microscopic scale, and they indicated that inclusive strategies depend on approaches focusing on the pedagogical work as a whole and for all students. When the approach was limited to isolating children to prevent their particularities from disturbing others, access clearly did not offer a way of joining in the activities compatible with an inclusive school life. The text concludes with an analysis of scenes observed and, based on the study conducted, and argues that access does not always result in inclusion

\section{Keywords}

Access - Participation - Inclusive school life.

\section{Introdução}

Este artigo aborda a presença de crianças com deficiências em escolas públicas. Seu objetivo é argumentar, com base em exemplos, que o acesso à escola não é suficiente para que se tenha uma vida escolar inclusiva. Apresentamos uma análise que se baseia em cenas registradas nos cadernos de campo de etnografias realizadas em escolas públicas a partir de 2014 e que têm oferecido base concreta para abordar o tema inclusão a partir do chão da escola pública. ${ }^{3}$

0 acesso de alunos com deficiência à escola pública é objeto de pesquisa de inúmeros autores do campo educacional brasileiro e proporciona, há pelo menos três

3- Escolas e personagens citadas têm, aqui, nomes omitidos para preservação de identidades e instituições. Os projetos que deram origem às informações analisadas foram aprovados em comitê de ética e nas instâncias competentes da Universidade Federal de São Paulo (Unifesp). Processos n 714.065/2014 CEP e 13.300 PROEC. 
décadas, interlocução crescente entre esses pesquisadores da educação e aqueles que, em outras áreas de conhecimento, também abordam a complexidade do tema.

Estudos históricos que explicitaram dinâmicas de segregação, processos de institucionalização e a própria configuração da educação especial em suas singularidades (BUENO, 2004; JANNUZZI, 1985; MAZZOTA, 1996; SOARES, 2006), fazem parte de um repertório crítico e multifacetado que se desdobrou em inúmeras trajetórias de pesquisa (JESUS et al., 2011) e consolidou debates que explicitaram tensões entre políticas, discursos e práticas relacionadas ao universo da educação inclusiva (KASSAR; ARRUDA; BENATTI, 2011).

A aproximação entre pesquisadores da educação e autores que atuam em outras frentes de análise, desde o final da década de 1980, tem refinado a abordagem de complexidades específicas, como as que buscaram inspiração fenomenológica para abordar a presença de crianças cegas em escolas regulares (MASINI, 2013); as que buscaram autores como Pessotti (1984) para pensar a escolarização de crianças com deficiência intelectual (CARVALHO, 2006); as que se beneficiaram da leitura de Pino (2010) para a apropriação da fortuna crítica de Vygotsky e outras tantas que permitem afirmar que o campo educacional brasileiro discute educação inclusiva permanentemente e com ampla abertura interdisciplinar.

Ferreira (1994), Sousa e Prieto (2002) e Prieto (2002, 2006) discutiram o especial da e na educação especial, e os já citados Kassar, Arruda e Benatti (2011) insistiram que abordar o tema inclusão na escola exigiria criticar simultaneamente a ordem econômica que a contém.

Laplane (2004, 2010), Góes (2004) e Ferreira (1994) abordaram a dimensão política que necessariamente deveria ser considerada para se pensar a escolarização de crianças com deficiências nos termos da educação inclusiva.

Padilha (2001), Michels (2005), Freitas (2013), Freitas e Prado (2017) discutiram a complexa trama que envolveu a formação de professores e suas expectativas em relação à presença de alunos com deficiência nas classes comuns das redes públicas, tema também abordado por Molina (2016).

Smolka e Goes (1997) e Smolka (2004) estabeleceram parâmetros densos para a educação inclusiva que repercutiram em muitos estudos no campo educacional, o que colaborou para que essa questão fosse trabalhada levando em conta a relação do sujeito incluído com o conhecimento.

Rahme $(2014,2018)$ tem se valido das contribuições da psicanálise para pensar o tema dentro do campo educacional brasileiro, e Martínez e Rey (2017) argumentam que a escolarização de crianças com deficiências também diz respeito à interlocução entre educação e psicologia social.

Educação inclusiva não diz respeito somente ao tema das deficiências. E a polissemia de uma categoria que é necessariamente permeada por questões de classe, raça, etnia, gênero (BRAH, 2006; HIRATA, 2014; MELLO; NUERNBERG, 2012) indica que inclusão é um território analítico tanto mais crítico quanto mais disposto a reconhecer a interseccionalidade entre problemas que são cumulativos.

0 esforço de aproximação que será aqui apresentado, quase um mergulho na lâmina do microscópio (WOODS, 2010), se inspira em autores que realizaram etnografias em cenários de grande complexidade, considerando a presença de crianças em corporeidades singulares 
e com expressivas reduções de mobilidade (BIZERRIL, 2015; BLUEBONDLANGNER, 1980, 1990; CSORDAS, 2014, 2015).

Não são referenciais novos, mas são autores pouco citados no campo educacional brasileiro. Essas referências nos ensinaram que interações etnograficamente flagradas revelavam que, ao contrário do que parecia ser a inércia de corpos que pouco ou nada se movem sem auxílio, ocorria a recriação microscópica da linguagem que passava a operar associadamente ao corpo de outrem, ou ao apetrecho, ou ao aparato tecnológico.

Concretamente, foi o acompanhamento da recriação microscópica da linguagem que nos permitiu afirmar que o acesso não é suficiente para garantir uma vida escolar inclusiva. É o que mostraremos a seguir.

\section{Lupas, inventários e reduções de mobilidade}

Nas pesquisas sobre inclusão, há situações que exigem investigar de perto, de muito perto, constantemente e com atenção a movimentos ínfimos que "podem não se repetir" (GOFFMAN, 2010).

Essa foi a base metodológica para este artigo que apresenta alguns cenários, cenas e ações mediadoras nas quais a presença de crianças em escolas públicas, duas com deficiência múltipla e uma com paralisia cerebral, suscitou a oportunidade de realizar uma pesquisa em escala microscópica e efetuar comparações.

É na escala microscópica que a criança que vive a experiência da deficiência múltipla ou da paralisia cerebral demanda um "inventário de gestos" (CSORDAS, 2014; GEBAUER; WULF, 2004), com o qual a interação possível mostra-se na unidade mimética, significativa, ainda que efêmera, entre corpos, olhares, apetrechos e estratégias.

Foi possivel confirmar que estratégias inclusivas têm efeitos consideráveis na mitigação de desvantagens pessoais, especialmente quando a criança não é considerada somente como "derivada de sua deficiência” (GOFFMAN, 2012).

Aproximamos a lupa ao chão de duas escolas públicas para dar visibilidade à presença de três crianças. Essas têm a experiência de corpo (MERLEAU-PONTY, 2000) configurada na redução de mobilidade e em limites de ordem comunicacional.

Nossa intenção é a de compartilhar como a trama de cada situação foi decisiva para compreender o que se tornou, para cada uma, o acesso, a participação e a própria vida escolar, que nem sempre foi inclusiva.

\section{Cenários e personagens}

Os cenários se estruturaram em duas escolas públicas.

Uma escola fica na cidade de São Paulo, onde acompanhamos duas crianças, doravante denominadas Helena e Alice, e a outra escola fica na cidade de Guarulhos, onde acompanhamos Nanci.

Helena e Alice são mencionadas em quase todas as situações de suas vidas com base nos comprometimentos motores, sensoriais, intelectuais e de comunicação associados à deficiência múltipla (DMU). A experiência de Nanci está associada à paralisia cerebral (PC). 
A PC apresenta grande variedade de características. No caso de Nanci, o quadro não é de demasiada severidade. Ela não depende, por exemplo, de cadeiras de roda. Mas tem traços de uma diparesia espástica, ou seja, há comprometimento de ambos os braços, mas nas pernas os efeitos da PC são mais acentuados. Tem a fala comprometida.

Helena e Alice estão no primeiro ano do ciclo de alfabetização do ensino fundamental, e matriculadas em turmas diferentes. Participam também do Atendimento Educacional Especializado (AEE). Nanci está na educação infantil.

Vamos caracterizar e analisar primeiramente Helena e Alice. Após, dedicaremos atenção à experiência de Nanci. Esse critério de exposição é importante, pois, ao final da caracterização de Nanci, queremos suscitar um debate específico, defendendo que inclusão exige mais, muito mais que o acesso. Só será possível demonstrar isso se a situação de Nanci puder ser comparada à situação das duas primeiras.

\section{Cenários e cenas de Helena}

Helena e Alice são acompanhadas por Auxiliares da Vida Escolar (AVE) e estagiárias de Pedagogia. São consideradas a razão de ser da Sala de Apoio e Acompanhamento à Inclusão (SAAI) e protagonizam cenas em que o trabalho escolar não está centrado unicamente na relação direta entre professor e aluno, uma vez que mobilizam pessoas consideradas coadjuvantes da ação docente.

A cena em que Helena foi vislumbrada se desenrolava ao redor de um colchão no corredor em frente à SAAI. A criança sobre o colchão estava rodeada pela mãe, pela professora e pela AVE. Todas falavam dela, e nenhuma com ela, a respeito do que se daria na sequência.

0 transcorrer da pesquisa confirmou inúmeras vezes que o olhar adulto se dirigia especificamente para ela quando mobilizado por um grito seu. Sem o grito, o desencontro permanente entre os olhares suscitava a impressão daquilo que Goffman define como "presença ignorada" (GOFFMAN, 2013, p. 63).

Helena estava de bruços no chão, movimentava as pernas e se encolhia. Era uma criança que mostrava, a seu modo, elaborar a realização de seus intentos em seu paralelismo. Tanto é que, após ganhar e comer um chocolate, deslocou-se para outro lugar para deixar-se ao sol (GOFFMAN, 2009). Seu deslocamento sempre foi considerado um rastejar por todos os que a cercam.

A AVE foi buscá-la, mas ela não se manteve no colchão. Escolheu um local para ficar e sentou-se rapidamente, balançou os braços, vocalizou, emitiu sons diversos e gargalhadas.

A particularidade de suas ações e reações suscitava comentários a respeito da incompatibilidade entre sua presença e a escola, pois ela muitas vezes podia ser flagrada em situações de desconexão com os trabalhos escolares, como quando a professora trabalhava com os demais alunos e Helena permanecia sozinha, condição que se modificava apenas com a aproximação intermitente da AVE.

Observamos, por meio de algumas cenas no refeitório, com alternância entre os momentos de agitação e de aquietação de Helena, que muitos tinham expectativas de que a escola pudesse exercer sobre ela um efeito adestrador. 
A oferta de chocolate quando a criança reagia manifestando sua discordância em relação ao local que lhe fora atribuído lembrava o que Goffman comentou ao se referir aos instrutores de uma escola especial que se dirigiam aos alunos de modo semelhante a como faziam com os cães:

[...] a cidade que tem uma escola de treinamento de cegos aprende a olhar com aprovação os estudantes que seguram um arreio atado a um instrutor humano enquanto dirigem a este palavras de estímulo semelhantes às que se costuma empregar para um cão. (GOFFMAN, 2013, p. 63).

Registramos situações em que Helena foi posicionada de costas para os acontecimentos da sala. Assim, agitava-se rapidamente. As demais crianças tentavam intervir abrindo interlocução direta com Helena, mas a exaltação da professora ampliava a dificuldade e, via de regra, a determinação era para que saíssem de perto dela e a "deixassem em paz". Quanto mais alto falava a professora, mais agitada e chorosa reagia Helena.

Momentos de enternecimento, nos quais a professora segurava as mãos de Helena e, com ela, participava de atividades musicais podiam ser interrompidos com rispidez se a menina se agitasse: "Jesus Cristo Helena!"

Não foi possível identificar, em muitos meses de pesquisa, qualquer proposta voltada a ela. Sempre pareceu ser suficiente acionar a AVE ou a estagiária para que pudessem “desligá-la” ou retirá-la quando necessário.

\section{Das referências àquela outra}

A desconexão com Helena por vezes se quebrava de forma singular, quando, por exemplo, entrava em questão falar de inclusão.

0 recurso para tocar no assunto com aquele grupo de crianças era sempre a fábula infantil.

Foi com a fábula da galinha que botava ovos quadrados que o tema foi tratado pela primeira vez, num contexto em que Helena se manteve com as pernas flexionadas, cotovelos apoiados nos joelhos e apoiando o queixo nas mãos.

0 "filho da galinha", um pintinho, era a personagem seguidamente rejeitada por ter sua origem num ovo quadrado.

A professora pediu às demais crianças que comparassem a situação de Helena com a do bichinho. A reação não foi espontânea, não se estabeleceram imediatamente analogias. Mas, com insistência, a turma concordou que havia semelhanças entre a fábula e Helena.

A situação foi interrompida com choro e gritos de Helena, que foi contida com gritos da professora: “Jesus Cristo!” Um colega de Helena tentou interferir, mas foi censurado.

As táticas de pacificação, que não se reduziam às cotas de chocolate, tinham apetrechos próprios. Entrou em cena a chupeta, porém os efeitos tranquilizadores da tática foram efêmeros, retornando a agitação.

Como tática seguinte, Helena foi transferida para a AVE.

Se o chocolate foi associado às estratégias de adestramento, a chupeta deve ser destacada no âmbito do apetrechamento que se reserva à criança com DMU. 
Se a cadeira de rodas se conecta ao fluxo do corpo (HARAWAY, 2016), tornando-se, muitas vezes, os pés circulares da criança, é com esses pés próprios que ela é tirada e conduzida para outros territórios da escola quando as outras táticas não surtem efeito.

A pesquisa comprovou que as táticas e estratégias previamente pensadas são todas, sem exceção, relacionadas ao silenciamento e recomposição da tranquilidade.

A base material da presença de crianças com redução de mobilidade se diversifica com técnicas de manejo do corpo, por exemplo, a calça da vovó ${ }^{4}$. Foi numa calça de vovó que registramos Helena explorando desenhos ladrilhados no piso.

Quando sorriu, Helena sorriu sozinha.

\section{De objetos e utensílios}

A presença de uma criança com DMU na escola suscita estratégias que também se materializam em objetos e utensílios de contenção. No caso de Helena, a AVE trouxe uma mesa adaptada que acoplava sua cadeira.

Algum efeito surtiu essa tática, porque, na sequência, cessaram gritos e mordidas. Mas a contenção também evitava a livre movimentação dos braços e das pernas.

Ela passou a usar óculos e foi numa cena em que a armação com as lentes era quase destruída que foi possível observar a imediata sobreposição de cenas (GOFFMAN, 2010), com a entrada de outra criança no território em que a corporeidade de Helena estava contida.

Outra criança que interveio com calma e persistência, tocando-a nas mãos, pedindo que não insistisse até quebrar os óculos.

Isso permitiu registrar nos cadernos de campo que os territórios especificamente designados para Helena começaram a receber objetos com maior ou menor potencial tranquilizadores, inibidores de movimento, ou voltados para entretenimento.

Foi possível registrar algumas visitas das demais crianças a esse território. Nessas ocasiões, os colegas de Helena lhe concediam carinho, afagos e afetos.

0 fato é que se constituiu, como ensina Goffman (2011), um território pessoal, que foi se elaborando com suas marcas. Helena aprendeu, com o passar dos dias, a reconhecer e estabelecer as relações de conforto e desconforto em seu lugar na sala de aula. A criança com deficiência muitas vezes experimenta a dialética da configuração de "seu lugar" no mundo (MURPHY, 2005). Isso quer dizer que em pouco tempo não é mais possível separar o quanto a criança está num lugar porque é deficiente do quanto é deficiente porque está num determinado lugar.

\section{Posicionamentos e marcações}

Os pontos de vista, ou seja, a configuração dos espaços a partir dos quais o olhar de Helena se somava ao seu posicionamento, eram influenciados pela relação que se estabelecia entre professora e estagiária.

4- É uma calça de adulto que pode ser preenchida com espuma e tecido, onde se costuram as aberturas, barra e cintura; precisa ser pesada, mas flexível, pois pode ser usada para posicionamento da criança no chão, sem apoio de um adulto. 
Essa confirmação foi possível em muitos registros e especialmente num dia em que a professora dedicou-lhe especial afeto, recebendo-a na porta da sala e, na sequência, posicionando sua cadeira para proporcionar um ângulo de visão que abrangia todo o movimento da sala.

Porém, a estagiária mudou o posicionamento assim que chegou. Essa modificação reduziu e concentrou o campo de visão da menina, mas a professora não interferiu, pois a responsabilidade passava a ser da estagiária assim que chegava.

Naquele momento, a estagiária já organizava seu campo de interações com Helena com base nos resultados de experiências de controle anteriores. Sabia que a mesa a mantinha calma e controlada. Com o encaminhamento desse encaixe obteve o resultado esperado, mas reduziu a si o campo de visão da criança.

Esses distanciamentos entre os campos de visualização de todas as personagens do cenário favorecia a identificação da presença de Helena com sonoridades associadas a ela.

Ou seja, nas dinâmicas que reduziam as possibilidades de suas interações visuais e que, como ensina Goffman (2014), impediam que ela "pegasse a atenção de alguém com os olhos", Helena passava a ser percebida pelos demais quando o seu território produzia barulhos dissonantes.

Essa situação favorecia desligamentos temporários de suas sonoridades, como quando de sua caixa rosa foi retirada uma revista para ela rasgar. 0 entretenimento com o rasgar pareceu satisfazer a todos, pois ela estava simultaneamente ocupada e quieta.

Só foi possível perceber com clareza que Helena comunicava interesse ou desinteresse, satisfação ou insatisfação, com o adensamento da atenção nas particularidades de suas sonoridades e gestos. No entanto, ocorria o que Lane (2012) denomina de "elemento deficientizador" no plano das interações e que diz respeito àquilo que concretamente a pessoa com deficiência encontra nos espaços que é chamada a fazer parte.

No caso concreto de Helena, o modo de perguntar era um modo de impedi-la de responder. E as estratégias para produzir respostas coletivas eram as que mais claramente deficientizavam seu modo de responder.

As diferenças podem ser deficientizadas e marcadas e essas marcações podem ser acionadas por qualquer personagem da trama. Um exemplo disso foi recolhido quando duas estagiárias falaram não com Helena, mas de Helena: ela é "negra, mas não negona como Alice [...]".

0 estrangeirismo de Helena se mostrava numa soma de desvantagens: negra e deficiente, mas comparada com outra criança com deficiência, mais deficiente do que negra.

As crianças inventavam brincadeiras para distrair Helena, ainda que o fizessem tratando-a como um bebê. Crianças de outras turmas se aproximaram dela, mas eram sempre advertidas pela professora: “[...] não, aqui não é ponto turístico”.

Vamos trazer ao foco (GOFFMAN, 2010) Alice, sempre comparada com Helena.

\section{Outra personagem}

Alice muitas vezes sorriu enquanto as demais crianças faziam a leitura do alfabeto em coro. Entretanto, sua experiência também foi marcada por longos momentos de ociosidade. 
A professora passava por sua mesa, nem sempre interagindo com ela. Mas a aproximação de outras crianças não era inibida e claramente resultava em efeitos tranquilizadores. Ela retribuía sorrindo.

Nos primeiros encontros, não foi possível visualizar nenhum material de atividade adaptado para ela.

Foi possível observá-la, seguidas vezes, alimentando-se na companhia da AVE, com suas técnicas de comer vagarosas, que lhe permitiam observar enquanto lentamente mastigava.

Postava os olhos para comunicar-se e, quando "pegava um olhar" (GOFFMAN, 2014), sorria.

O lugar de Alice foi defınido na primeira fileira, a mais próxima da porta. Havia três adultos na sala para 28 crianças: professora, mais duas estagiárias.

Um dos apetrechos de Alice que ajudava a demarcar suas particularidades era o babador.

Registramos quando tentou pegar o livro de outra criança. Quando demonstrou com os braços também desejar receber um exemplar, foi possível constatar que, assim como Helena, Alice viveu inúmeras situações de não presença (GOFFMAN, 2012), pois experimentou recusas baseadas na dificuldade de se reconhecer o que não é pedido de forma verbalizada.

É importante registrar que a escola documentava que Alice tinha sérios comprometimentos na mobilidade dos membros superiores, com prejuízo motor das mãos e dos braços. Mas o caderno de campo da pesquisa documentou exatamente o contrário.

Ela empreendia movimentos de elevada complexidade motora, com uso efetivo dos braços e com técnicas bastante efetivas para realizar, com movimentos, o que quisesse.

Esse foi (é) um expressivo dado de invisibilidade, decorrente da certeza prévia de que, conhecido o diagnóstico, já se sabe o que a pessoa é ou não é (GOFFMAN, 2012).

Alice convivia com Helena algumas vezes no pátio e seus modos sorridentes faziam com que as demais crianças se demorassem mais com ela, o que, nessas situações, ampliava as desvantagens de Helena.

Alice conseguia frequentemente protagonizar processos que Goffman (2010) considera organizadores da distância que se tem em relação aos demais, observáveis em situações microscópicas. Com os braços (e abraços), Alice regulava aproximações e distanciamentos e demonstrava que sorrir era uma técnica acionada para obter aproximação.

Numa situação de leitura coletiva do alfabeto foi possível registrar a ação concatenada de Alice balançando o braço esquerdo no ritmo da fala e com atenção focada na condução da professora. Portanto, ela estava participando.

Foi percebida folheando um caderno, o que, evidentemente, só é possível com o material ao alcance da mão; e registramos momentos em que a professora se aproximava especificamente de Alice para mostrar-lhe as ilustrações enquanto lia uma fábula para todas as crianças. De sua parte, Alice reagia a esse movimento de partilha tentando reter o livro para si.

Se por um lado as sonoridades se sobressaíam às vocalizações de Alice, impedindo sua entrada nos campos verbais de solicitação da professora; por outro lado, era em meio às cenas com mais barulho que ela demonstrava suas tentativas de compreender o que se passava. 


\section{Entre pares, tarefas e lugares}

A presença de Alice (e também de Helena) por vezes exercia sobre as demais crianças um "efeito síntese de impossibilidades" (COLEMAN, 2012). exemplar.

Para deixar mais claro o que essa síntese significa, uma situação recolhida é

Um garoto que convivia com Alice em sua sala de aula conheceu um menino de outra sala que era também uma criança com deficiência.

Ao perceber seu diálogo com a AVE, perguntou admirado: “Ele fala?”, manifestando sua perplexidade sobre o falar na pessoa com deficiência.

Uma das questões mais complexas do cotidiano da deficiência múltipla é a sobreposição de deficiências, o que em algumas circunstâncias instala limitações por derivação de outras experiências.

É possível também constatar que muitas atividades são feitas para a criança e não com ela. Num momento de tensão especificamente relacionado à presença de Alice, foi possível perceber um aspecto singular disso.

Quando a professora ficou temporariamente sem o auxílio da estagiária, a AVE entrou e organizou o ambiente para a chegada de Alice. Com essa organização, quando ela estava na sala, seu caderno permanecia em sua mesa. Recebia várias atividades como caça-palavras, procure a letra, palavras-cruzadas, figuras para pintar e colar.

Todavia, as atividades não tinham adaptações e, diferentemente do que costumava acontecer, permaneceram incompletas. 0 que se percebeu é que, antes, eram realizadas pela estagiária na escola e pela família em casa. Em casa, a família afirmava fazer com ela, mas percebemos que essas pessoas faziam para ela.

Para Goffman (2009), nas instituições, os territórios são defınidos pela incidência da autoridade. Sua permanência era definida conforme a estratégia de manter a deficiência sob controle.

Era do seu lugar à parte que, mesmo quando a estagiária estava presente, Alice procurava pela professora com os olhos, tomando-a como referência, fazendo com que muitas vezes fosse a estagiária a personagem como dificuldade para pegar seu olhar.

Essa predileção pelo olhar da professora se confırmou numa ocasião em que sua mãe explicou um episódio de choro. Ela chorou porque não queria voltar para casa, pois tinha a expectativa de permanecer perto da professora.

Se o lugar de sua permanência a desligava para permanecer sem atrapalhar, ela religava o contato com a professora independentemente dos esforços para mantê-la em seu território, produzindo o que Goffman (2012) denomina de "território do eu".

\section{A produção do externo e do interno}

As situações nas quais os modos de fazer foram integralmente repensados considerando a presença de Alice foram as que se estenderam em festividades extra-sala de aula. 
Numa festividade com dança, por exemplo, sua participação foi efetiva, alegre e bem-sucedida. Isso possibilitou registrar as reações da mãe que declarou sua convicção de que a escola era "o melhor local para a filha estar".

Entretanto, as atividades externas não se revelaram sempre inclusivas. A escola aderiu ao projeto CEU Itinerante, referência ao Centro Educacional Unificado instalado em unidade vizinha.

Treze alunos com deficiência foram levados para participar do projeto, em horário de aula. No espaço estavam três profissionais do projeto, mais a AVE e a professora da SAAI. Mais tarde chegaram mais cinco alunos, totalizando dezoito crianças, sendo que algumas foram encaminhadas porque eram consideradas com suspeita de deficiência.

Alice participou das atividades em sua cadeira de rodas. Sorria e era empurrada por alguém sempre que fosse necessário mudar de posição. Ela estava alegre, mas alternava momentos de atenção visual e aparente desligamento do contexto.

Helena, com suas demonstrações de incômodo, foi sendo deixada à parte nas atividades, a ponto de em dado momento ficar completamente isolada. atividade.

0 critério para que se mantivesse a conexão com a criança era sua integração à

Essa separação dentro da separação se repetiu noutra saída específica para as crianças com deficiência, em que a atividade desenvolvida era produzir pequenos óculos. Helena foi acalmada com a chupeta e não recebeu qualquer auxílio relacionado à atividade.

Confirmava-se, mais uma vez, que Helena recebia aproximação efetiva quando a demanda era silenciá-la. Quando já estava em silêncio, acontecia aquilo que Hugues e Patherson denominam “desaparição do corpo” (HUGUES; PATHERSON, 2017).

Quando a AVE indagou se Helena deveria ser levada para dormir ou receber cuidados de higiene, recebeu a sugestão de fazer com que ela participasse a seu modo.

Ao receber tinta, rolo de papel higiênico e outros itens da atividade, e também explicação sobre o que fazer, Helena explorou os materiais de forma singular e tomou parte.

\section{Diálogos construídos}

A pesquisa permitiu dialogar seguidamente com a professora sobre Helena.

0 diálogo com professores e o levantamento de suas opiniões deve sempre levar em consideração que esse profissional também fala de um lugar que não se restringe à perspectiva técnica do fazer e do não fazer. A opinião professoral (MARIN, 2006) é permeada pelas próprias contradições que também atuam na configuração das dificuldades docentes.

A professora enfatizava o quanto Helena era querida, mas, simultaneamente, manifestava reservas ao excesso de cuidados que as demais crianças dedicavam a ela.

Ao mesmo tempo em que as demais crianças revelavam ciúmes em relação às muitas formas e pessoas que lidavam com as demandas de Helena, essas mesmas crianças lhe dedicavam, na perspectiva da professora, um tratamento mais condizente com um bebê.

A professora reconheceu que às vezes não a incluiu na contagem dos presentes, mas sempre teve o respaldo de outras crianças que marcaram a importância de "contar Helena". 
Orgulhou-se quando afirmou que se relacionava mais afetivamente com Helena do que com os demais, lembrando que nas atividades externas ofereceu seu colo para mediar o deslocamento e em situação festiva dançou somente com ela.

Contou que suas estratégias afetivas eram os beijos, abraços e "cheiradas".

Compartilhou sua dificuldade para compreender as nuanças de seus choros, muitas vezes relacionados a momentos de dor ou fome. Foram manifestações surpreendentes, não confirmadas na dinâmica de observação.

0 deslocamento de Helena, que foi distanciada em relação ao lugar da professora para um microterritório na sala de aula, foi justificado com base "nas necessidades dos demais".

Na organização de seu "juízo" sobre o assunto (MARIN, 2006), a professora questionava a família da criança, especialmente a mãe por "não ter percebido" mais prontamente as dificuldades da fala e do movimento.

Reconheceu que testou Helena quando elevou a voz para deixar claro que tinha autoridade sobre ela e demonstrar que, naquele espaço, "não era sua mãe".

Queixou-se da ausência de laudo e de acompanhamento e, principalmente, daquilo que a seu ver era uma resistência da mãe a agir como quem reconhece a deficiência.

A mãe se referia à experiência escolar de Helena aludindo ao que ela considerava ter sido uma perda. Em sua opinião, a experiência na Escola de Educação Infantil fora mais adequada, inclusive em termos materiais.

As expectativas da mãe e da professora convergiam no momento em que escolhiam a palavra autonomia para indicar o que de mais significativo poderia ser acrescentado no futuro. Essa coincidência fez lembrar as etnografias coordenadas por Harkness (2000), na Europa e na África, em que a autora identificou no cotidiano o que foi por ela designado de etnoteorias da parentalidade.

Nessa pesquisa, um amplo espectro de observação cobriu o cotidiano de centenas de mães; ao mesmo tempo, a teórica foi catalogando o acervo de palavras com as quais os adultos descreviam situações em que a criança poderia ser considerada menos vulnerável.

Nas circunstâncias mais estáveis, ou seja, em locais com menor incidência de desigualdades sociais, as palavras-chave para indicar a presença de uma criança menos exposta à vulnerabilidade eram limpa, alimentada e com sono tranquilo.

No entanto, à medida que os pesquisadores foram se deslocando para locais em condições e situações mais adversas, as palavras-chave citadas pelas mulheres adultas foram outras. As crianças foram descritas como menos vulneráveis com as palavras alimentadas, acompanhadas e autônomas. A inserção das palavras e signos da autonomia permite entrever as situações em que a criança é mencionada "por dentro" das dificuldades adultas (HARKNESS, 2000).

As professoras se referiam aos ganhos de autonomia das crianças em questão mencionando a sobrecarga docente, dado inegável em todas as circunstâncias analisadas e que marca a docência no Brasil (MARIN, 2006).

\section{Outros diálogos}

Com a professora de Alice também foi possível manter seguidos diálogos. Ela percebeu que a aluna interagia através de suas expressões faciais, identificando, por exemplo, os 
momentos em que se pronunciava energicamente, com a "autoridade da bronca". Expressou, de forma emotiva, seu entendimento de que Alice era muito feliz na escola.

Para as demais crianças, Alice deveria ser tratada sem distinção, inclusive em relação às tarefas escolares para casa.

A professora sabia que a família fazia suas lições de casa, mas também afirmava, com certa tensão, que pouco ou nada sabia sobre a garota, apenas o que estava presente no cotidiano da escola. Nesse sentido, manifestava aborrecimento em relação ao desentrosamento com a SAAI, potencial provedora das informações precisas sobre a condição de Alice.

Sobre as expectativas em relação à presença de Alice, predominava o elogio ao pequeno gesto, por exemplo, a diminuição das vezes em que o caderno fora jogado ao chão. A professora manifestou-se favoravelmente aos processos inclusivos e aos direitos subjetivos emanados da inclusão. Considerou professores e demais alunos como principais beneficiários do convívio com crianças com deficiências. Em sua opinião, a maioria dos alunos não tratava Alice tomando como ponto de partida a deficiência, tanto que flagrou situações em que mostravam a língua para ela, sem condescendência.

Nas aproximações com a mãe, identificamos que ela era, formalmente, tia de Alice. Nessa condição, deparou-se com uma criança com um quadro de convulsões e diagnósticos não conclusivos de encefalopatia crônica. Os médicos nunca tinham utilizado a palavra deficiência nas considerações sobre Alice.

Sentiu-se malrecebida pela equipe da escola. Teve receio de matricular a criança e escutou da própria coordenadora que a escola não era o melhor lugar para ela.

Durante um dos diálogos que mantínhamos com a mãe, Alice pediu e manejou um tablet, escolhendo vídeos de sua preferência. Demostrou igual desenvoltura manejando um telefone celular, localizando imagens.

Em relação às expectativas, a seu modo a mãe recriava o que acontecia na escola. Apropriava-se da dificuldade de projetar e, por isso, expressões como "estou vivendo o presente" eram comuns.

\section{Da comparação que se mostrou possível: a personagem Nanci}

Quando as interações se mantiveram atentas aos repertórios de gestos de Helena e Alice, foi possível percebê-las participando do fluxo de atividades em andamento nos tempos e espaços da escola. Mas isso ocorreu pouco com Alice e quase nada com Helena.

Predominantemente, os apetrechos próprios de cada uma funcionavam como tecnologias de recomposição do silêncio. Na perspectiva das etnoteorias da parentalidade proposta por Harkness (2000), Helena e Alice seriam consideradas menos vulneráveis quando estivessem em silêncio, imóveis e limpas.

Em continuidade ao estudo, identificamos anotações de outros cadernos de campo, com situações concretas que permitiriam indicar porque, em nossa opinião, a matéria etnográfica da pesquisa com Helena e Alice revelava aspectos que ajudavam a compreender 
o acesso, mas que deixavam dúvidas sobre a inclusão, sobre os modos de permanecer (FREITAS, 2013).

Percebemos, assim, a importância de estabelecer uma comparação desses casos com a experiência de Nanci.

Como indicado no início deste trabalho, Nanci é uma criança diagnosticada com paralisia cerebral decorrente de complicações no parto, precoce e bastante problemático.

Sua presença na educação infantil de escola pública da cidade de Guarulhos acrescentou grande complexidade à professora, que a recebeu e trouxe para si a responsabilidade de organizar estratégias inclusivas com todas as crianças.

Foi bem de perto que conseguimos constatar que a ação da professora na inserção de Nanci tinha um acerto estrutural que exerceu efeito estruturante sobre todas as ações tomadas dia após dia.

Gradualmente, a professora foi percebendo elementos deficientizadores na materialidade e nas relações interpessoais do cotidiano. A partir dessa observação, desenvolveu estratégias que conseguiram impedir ou mitigar a deficientização.

A educação infantil tem um formato que inibe os excessos de aferições da educação escolar iniciados já nos primeiros momentos do ensino fundamental. Por isso, o fator tempo incidiu de modo diferente se comparado às condições concretas das professoras de Helena e Alice.

A professora de Nanci passou a dirigir-se a todas as crianças relativizando a importância da rapidez na conclusão de atividades, deslocando a atenção para os diferentes modos de fazer em cada pequeno trabalho.

Como cada tarefa necessariamente mobilizava objetos, brinquedos e variados recursos lúdicos, a localização e o acesso a cada item eram questão pedagógica das mais estratégicas.

Nanci não estava sendo chamada a adaptar-se, e a professora colocava em questão todos os modos de fazer considerando sua presença.

Registramos que o espaço passou a ser permanentemente pensado para que não demarcasse um território para Nanci, que, inclusive, estava a cada semana adquirindo mais agilidade na marcha em pé. Seu deslocamento livre pela sala era um processo literalmente em andamento, com uma equilibração própria (MAUSS, 2000).

0 chão mostrava-se, em alguns momentos, um território inclusivo, pois, ao deslocar a atividade da taboa da mesa para baixo dela, era criado um modo comum a todos de flexionar o corpo em relação ao material usado, fazendo com que o transcorrer da tarefa não tivesse significativas diferenças no tempo de conclusão. Sentar-se à cadeira não era tão problemático para Nanci quanto permanecer nela.

Como as configurações de espaço poucas vezes exerciam efeitos deficientizadores, em muitos momentos Nanci conseguia ser tão ágil quanto e até mais rápida que os colegas. Fato notado nos registros dos momentos em que o corpo de Nanci predominou na disputa com outra criança com o respectivo uso da força, da sobreposição e até da mordida.

Aliás, o episódio da mordida demonstrou que a professora tinha uma complexidade a mais para trabalhar. 0 diálogo com a mãe a respeito proporcionou um episódio em que, diante das demais crianças, Nanci foi severamente ameaçada de levar uma surra, 
demandando intervenção firme da professora para que isso não ocorresse, sem garantias de que assim não se daria longe da professora.

\section{Territórios da fonação inclusiva}

Uma das estratégias com efeito mais inclusivo foi a contínua indicação às demais crianças para que prestassem atenção aos gestos com os quais "todos" apontavam quando queriam indicar algo.

A constância fez com que a atenção aos gestos fosse assimilada não como recurso compensatório para déficits na fonação, mas como recurso para procurar nos modos de quem fala o modo como está falando.

A atenção dos outros foi sendo alcançada com técnicas que posicionavam todos para ouvir o outro. Até a professora, para falar, posicionava-se num lugar em que o grupo pudesse perceber que estava com a mão erguida.

Estabilizou-se aos poucos a percepção de que esse era o modo de obter atenção, fazendo com que, ao perceber um protagonista em cena com mão erguida, todos soubessem que era necessário silenciar para escutá-lo.

As sequências de Nanci eram: mão levantada, captura dos olhares para o gesto, aguardo das condições para falar e, assim, falar gesticulando e apontando.

A estratégia moveu-se do todo para a parte.

Em pouco tempo, foi possível registrar situações em que crianças se cutucavam para pedir silêncio: "Olha, ela quer falar". Assim, havia como mudar a faixa de sonorização, capturando o olhar com os gestos da mão.

A atenção à fala do outro tornou-se tão natural, que nos registros de um dia em que uma professora eventual substituiu a efetiva e se pôs a bater uma caneca na mesa para obter silêncio, anotamos que a ação causou estupor.

Prontamente as crianças se puseram a explicar como se fala sem palavras, pois tinham assimilado que transitavam por um território de fonação inclusiva, uma fonação singular, que abrangia outras técnicas de corpo.

\section{Considerações finais}

Os exemplos apresentados foram recolhidos com os recursos da aproximação que os estudos etnográficos proporcionam. Ou seja, identificamos, nas situações em que havia proximidade, que os atores que protagonizavam as cenas se expressavam com base no que consideravam ser a atenção possível do outro.

Se, para uma criança, o fazer barulho era o único recurso para obter aproximação; para outra, o silêncio tornava-se um recurso que, em partilha com os demais, produzia conectividades baseadas numa governança coletiva das sonoridades. Em nossa análise, os sons não foram triviais.

Duas crianças, especialmente Helena, conviveram com tecnologias do silenciamento. À medida que, na maioria das vezes, sua presença foi lembrada através da emissão de barulhos e, com isso, os dispositivos de recomposição do silêncio que deveria predominar 
em seu território eram os apetrechos que fechavam a boca, reduziam o alcance das mãos e inibiam as pernas.

Em sentido oposto, as técnicas de obtenção de silêncio representavam para Nanci o manejo próprio de recursos para fazer parte de um território comum a todos.

É possivel objetar que deficiências diferentes estão sendo comparadas e que, por isso, uma distorção se estabelece à medida que diferentes consequências anatômicas, fisiológicas e intelectuais são reduzidas a um denominador comum que não existe. Contudo, podemos prontamente escapar dessa objeção com exemplos que nos façam refletir sobre os modos de se deixar pegar com os olhos (GOFFMAN, 2014), os diferentes modos de produzir com o espaço situações com maior ou menor potencial deficientizador. Portanto, não foram comparadas deficiências.

Outra objeção que pode ser feita é a de que duas crianças foram observadas no âmbito da escola fundamental e uma no âmbito da educação infantil. É um dado inegável e que pode, de fato, exigir a continuidade de pesquisas com a intenção de verificar se os tempos e espaços de cada fase escolar têm diferentes acréscimos de dificuldades para a ação inclusiva dos professores.

Teria a educação infantil mais recursos inclusivos que a educação fundamental e suas fases posteriores? Trata-se de uma pauta que não deve ser abandonada.

No entanto, propusemos argumentar que o acesso não conduz necessariamente à inclusão. E isso não é um exercício retórico. A condição concreta dessas três crianças possibilitou essa conclusão.

Trata-se de reconhecer que o acesso conquistado diz respeito e decorre dos esforços sociais para fazer adentrar, fazer chegar, equipar, eliminar barreiras. Diz respeito também aos esforços para ampliar intervenções especializadas com auxiliares, estagiários, intérpretes e prover com materialidades específicas (rampas, placas em braile, elevadores, recursos didáticos) todo espaço institucional, principalmente escolas, que não devem (e não podem) deixar de reconhecer a presença de pessoas com deficiências.

Em relação à presença de alunos com deficiências, a inclusão diz respeito aos esforços por reconhecer, no modo de fazer, o potencial excludente e deficientizador de procedimentos, tarefas, tempos e espaços. A inclusão muda quem recebe.

Pode parecer que a característica mais essencial da educação inclusiva seja a atenção específica à particularidade de determinadas crianças. Mas não há criança presente na escola sem particularidades.

A chance de abordar com maior densidade aquilo que está implícito na presença de uma criança com deficiência depende da forma de abordar o cenário, a trama no seu todo.

A presença de espaços e instâncias institucionais voltados especificamente para crianças com deficiências, como os AEE e, num dos casos aqui mencionados, o SAAI, podem indicar a ampliação de matrículas, ou seja, comprovar que para determinadas pessoas foi proporcionado o acesso.

Todavia, a inclusão ocorre mesmo quando as dinâmicas de segregação não são naturalizadas como se fossem consequências inevitáveis da deficiência. Sem articulações, conexões e estratégias que passem por todos, são produzidas, dentro e fora das salas, os espaços para que a criança com deficiência apenas fique com sua deficiência ou com seus pares. 
Produzidos com a lógica da não interrupção dos trabalhos que contam, as comprovações de acesso não são imediatamente comprovações de inclusão.

Aproximamo-nos de três crianças e sabemos que a presença de cada uma delas na escola pública resultou do direito ao acesso que custou e custa contínuas lutas sociais. Mas, dentre as três, nos pareceu que Nanci experimentou efetivamente o sabor da inclusão.

Ou seja, o que tornou inclusiva a situação de Nanci em relação à de Helena e Alice não foi a particularidade da sua deficiência, mas o compromisso da escola com o que ela tem em comum com todas as crianças.

\section{Referências}

BIZERRIL, José. Notas para una cartografia de los estúdios sobre el cuerpo en Brasil. In: CITR0, Silvia (Org.) Cuerpo y corporalidades en las culturas de las Américas. Buenos Aires: Biblos, 2015. p. 77-88.

BLUEBOND-LANGNER, Mira. In the shadows of illness. New Jersey: Princeton University Press, 1980.

BLUEBOND-LANGNER, Mira. The secret life of dying children. New Jersey, Princeton University Press, 1990.

BRAH, Avtar. Diferença, diversidade, diferenciação. Cadernos Pagu, Campinas, v. 26, p. 329-376, 2006.

BUENO, José Geraldo Silveira. Educação especial brasileira: integração/segregação do aluno diferente. São Paulo: Educ, 2004.

CARVALHO, Maria de Fátima. Conhecimento e vida na escola. Campinas: Autores Associados, 2006.

COLEMAN, Lerita M. Stigma: enigma demystified. In: DAVIS, Lennard (Ed.) The disability studies reader. New York: Taylor \& Francis, 2012. p. 141-152.

CSORDAS, Thomas. Corpo, significado, cura. Porto Alegre: Edufrgs, 2014.

CSORDAS, Thomas. Embodiment: agencia, diferencia y padecimento. In: CITRO, Silvia (Coord.) Cuerpo y corporalidades en las culturas de las Américas. Buenos Aires: Biblos, 2015. p. 17-42.

FERREIRA, Júlio Romero. A exclusão da diferença. Piracicaba: Unimep, 1994.

FREITAS, Marcos Cezar de. 0 aluno incluído na educação básica: avaliação e permanência. São Paulo: Cortez, 2013.

FREITAS, Marcos Cezar de; PRAD0, Renata Lopes Costa. 0 professor e as vulnerabilidades infantis. São Paulo: Cortez, 2017.

GEBAUER, Gunter; WULF, Cristoph. Mimese na cultura. São Paulo: AnnaBlume, 2004.

GOES, Maria Cecilia. Desafios da inclusão de alunos especiais. In: GOES, Maria Cecilia; LAPLANE, Adriana Lia Friszman de (Org.). Políticas e práticas de educação inclusiva. Campinas: Autores Associados, 2004. p. 69-92. 
GOFFMAN, Erving. A representação do eu na vida cotidiana. Petrópolis: Vozes, 2011.

GOFFMAN, Erving. Comportamento em lugares públicos. Petrópolis: Vozes, 2013.

GOFFMAN, Erving. Estigma: notas sobre a manipulação da identidade deteriorada. Rio de Janeiro: LTC, 2009.

GOFFMAN, Erving. Manicômios, prisões e conventos. São Paulo: Perspectiva, 2010.

GOFFMAN, Erving. Os quadros da experiência social. Petrópolis: Vozes, 2014.

GOFFMAN, Erving. Rituais de interação: ensaios sobre o comportamento face a face. Petrópolis: Vozes, 2012.

HARAWAY, Donna. Antropologia do ciborgue. Belo Horizonte: Autêntica, 2016.

HARKNESS, Sara. Parental ethnotheories of children's learning. In: LANCY, David; BOCK, John; GASKINS, Suzanne (Ed.). The anthropology of learning in childhood. New York: Toronto: Altamira Press, 2000. p. 101-115.

HIRATA, Helena. Gênero, classe, raça. Tempo Social, São Paulo, v. 26, n. 1, p. 61-73, 2014.

HUGUES, Bill; PATERSON, Kevin. El modelo social de discapacidad y la desaparición del cuerpo. In: BARTON, Len (Comp.). Superar las barreras de la discapacidad. Madrid: Morata, 2017. p. 107-121.

JANNUZZI, Gilberta. A luta pela educação do deficiente mental no Brasil. São Paulo: Cortez, 1985.

JESUS, Denise Meyrelles et al. Inclusão, práticas pedagógicas e trajetórias de pesquisa. Porto Alegre: Mediação, 2011.

KASSAR, Mônica; ARRUDA, Elcia; BENATTI, Marielle Moreira. Políticas de inclusão: verso e reverso de discursos e práticas. In: JESUS, Denise Meyrelles et al. Inclusão, práticas pedagógicas e trajetórias de pesquisa. Porto Alegre: Mediação, 2011. p. 21-31.

LANE, Harlan. Construction of deafness. In: DAVIS, Lennard (Ed.). The disability studies reader. New York: Taylor \& Francis, 2012. p. 79-92.

LAPLANE, Adriana Lia Friszman de. Notas para uma análise dos discursos sobre inclusão escolar. In: GOES, Maria Cecilia (Org.). Políticas e práticas de educação inclusiva. Campinas: Autores Associados, 2004. p. 05-29.

LAPLANE, Adriana Lia Friszman de. Contribuições para o debate sobre a política de inclusão. In: LODI, Ana Claudia Balieiro et al. (Org.). Leitura e escrita no contexto da diversidade. Porto Alegre: Mediação, 2010. p. 27-32.

MARIN, Alda Junqueira. Manifestações de professores sobre alunos. In: FREITAS, Marcos Cezar. Desigualdade social e diversidade cultural na infância. São Paulo: Cortez, 2006. p. 224-249.

MARTíNEZ, Albertina Mitjáns; REY, Fernando González. Psicologia, educação e aprendizagem escolar. São Paulo: Cortez, 2017. 
MASINI, Elcie Salzano. 0 perceber de quem está na escola sem dispor da visão. São Paulo: Cortez, 2013.

MAUSS, M. Técnicas do corpo. In: MAUSS, Marcel. Antropologia e sociologia. São Paulo: Cosac Naify, 2000. p. 401-422.

MAZZOTTA, Marcos José Silveira. Educação especial no Brasil. São Paulo: Cortez, 1996.

MELLO, Anahi Guedes; NUERNBERG, Adriano Henrique. Gênero e deficiência: interseções e perspectivas. Revista de Estudos Feministas, Florianópolis, v. 20, n. 3, p. 635-655, 2012.

MERLEAU-PONTY, Maurice. A natureza. São Paulo: Martins Fontes, 2000.

MICHELS, Maria Helena. Paradoxos na formação de professores para a educação especial. Revista Brasileira de Educação Especial, Marília, v. 11, n. 2, p. 255-272, 2005.

MOLINA, Karina Soledad. A formação de professores para atuar na inclusão escolar. Journal of Research in Special Education Needs, v. 16, n. S1, p. 70-74, 2016.

MURPHY, Robert. The body silent. New York: Columbia University Press, 2005.

PADILHA, Ana Lunardi. Práticas pedagógicas na educação especial. Campinas: Autores Associados, 2001. PESSOTTI, Isaias. Deficiência mental. São Paulo: Edusp, 1984.

PINO, Angel. A marcas do humano. São Paulo: Cortez, 2010.

PRIETO, Rosângela Gavioli. Atendimento escolar de alunos com necessidades educacionais especiais: indicadores para análises de políticas públicas. Revista Undime, Rio de Janeiro, n. 1, p. 5-14, 2002.

PRIETO, Rosângela Gavioli. Atendimento escolar de alunos com necessidades educacionais especiais. In: ARANTES, Valéria Amorim Arantes (Org.). Inclusão escolar. São Paulo: Summus, 2006. p. 56-68.

RAHME, Mônica Maria Farid. A função da mediação na trajetória de um aluno com transtorno do espectro autista no ensino fundamental. In: BORGES, Adriana Araújo Pereira; NOGUEIRA, Maria Luísa Magalhães (Org.). Toda criança pode aprender: 0 aluno com autismo na escola. Campinas: Mercado de Letras, 2018. p. 291-313.

RAHME, Mônica Maria Farid. Laço social e educação: um estudo sobre os efeitos do encontro com o outro no contexto escolar. Belo Horizonte: Fino Traço, 2014.

SMOLKA, Ana Luisa Bustamante. A relação do sujeito com o conhecimento. 2004. 196 p. Tese (Doutorado em Educação) - Faculdade de Educação da Universidade Estadual de Campinas (Unicamp), Campinas, 2004.

SMOLKA, Ana Luisa Bustamante; GOES, Maria Cecilia (Org.). A significação nos espaços educacionais: interação e subjetivação. Campinas: Papirus, 1997. 
SOARES, Maria Aparecida Leite. A educação do surdo no Brasil. Campinas: Autores Associados, 2006.

SOUSA, Sandra; PRIETO, Rosângela Gavioli. A educação especial. In: OLIVEIRA, Romulado Portela; ADRIÃO, Theresa (Org.). Organização do ensino no Brasil. São Paulo: Xamã, 2002. p. 21-44.

WO0DS, Peter. La escuela por dentro: la etnografia en la investigación educativa. Barcelona: Paidós, 2013.

Recebido em: 08.10.2017

Modificado em: 24.04.2018

Aprovado em: 16.05.2018

Marcos Cezar de Freitas é professor associado livre-docente do Departamento de Educação da Escola de Filosofia, Letras e Ciências Humanas da Universidade Federal de São Paulo (Unifesp). Coordenador do Laboratório de Antropologia Educacional e Vulnerabilidades Infantis (LAEVI) e da Plataforma de Saberes Inclusivos.

Rosângela Nezeiro da Fonseca Jacob é doutora em educação e saúde na infância e adolescência pela Universidade Federal de São Paulo (Unifesp). Pesquisadora colaboradora do Laboratório de Antropologia Educacional e Vulnerabilidades Infantis (LAEVI). Diretora de Escola na Secretaria Municipal de Educação de São Paulo. 